\title{
Particle-size distributions and seasonal diversity of allergenic and pathogenic fungi in outdoor air
}

\author{
Naomichi Yamamoto ${ }^{1,2}$, Kyle Bibby ${ }^{1}$, Jing Qian ${ }^{1,4}$, Denina Hospodsky ${ }^{1}$, \\ Hamid Rismani-Yazdi ${ }^{1,5}$, William W Nazaroff ${ }^{3}$ and Jordan Peccia ${ }^{1}$ \\ ${ }^{1}$ Department of Chemical and Environmental Engineering, Yale University, New Haven, CT, USA; \\ ${ }^{2} J a p a n$ Society for the Promotion of Science, Tokyo, Japan and ${ }^{3}$ Department of Civil and Environmental \\ Engineering, University of California, Berkeley, CA, USA
}

\begin{abstract}
Fungi are ubiquitous in outdoor air, and their concentration, aerodynamic diameters and taxonomic composition have potentially important implications for human health. Although exposure to fungal allergens is considered a strong risk factor for asthma prevalence and severity, limitations in tracking fungal diversity in air have thus far prevented a clear understanding of their human pathogenic properties. This study used a cascade impactor for sampling, and quantitative real-time PCR plus 454 pyrosequencing for analysis to investigate seasonal, size-resolved fungal communities in outdoor air in an urban setting in the northeastern United States. From the 20 libraries produced with an average of $\sim 800$ internal transcribed spacer (ITS) sequences (total 15326 reads), 12864 and 11280 sequences were determined to the genus and species levels, respectively, and 558 different genera and $\mathbf{1 1 7 2}$ different species were identified, including allergens and infectious pathogens. These analyses revealed strong relationships between fungal aerodynamic diameters and features of taxonomic compositions. The relative abundance of airborne allergenic fungi ranged from $2.8 \%$ to $10.7 \%$ of total airborne fungal taxa, peaked in the fall, and increased with increasing aerodynamic diameter. Fungi that can cause invasive fungal infections peaked in the spring, comprised $0.1-1.6 \%$ of fungal taxa and typically increased in relative abundance with decreasing aerodynamic diameter. Atmospheric fungal ecology is a strong function of aerodynamic diameter, whereby through physical processes, the size influences the diversity of airborne fungi that deposit in human airways and the efficiencies with which specific groups of fungi partition from outdoor air to indoor environments.
\end{abstract}

The ISME Journal (2012) 6, 1801-1811; doi:10.1038/ismej.2012.30; published online 5 April 2012

Subject Category: microbial population and community ecology

Keywords: aerodynamic diameter; fungi; 454 pyrosequencing; allergen; bioaerosol

\section{Introduction}

An estimated $28-50 \mathrm{Tg}$ of fungal materials are emitted into the earth's atmosphere each year, and in some regions, fungal particles may constitute $>20 \%$ of the primary emissions of organic aerosol (Elbert et al., 2007; Heald and Spracklen, 2009). Airborne fungal material is an important contributor to human diseases. In industrialized countries, an estimated $20-30 \%$ of the population is affected by allergic diseases, and at least $3-10 \%$ of the general population are sensitized to fungal allergens

Correspondence: J Peccia, Department of Chemical and Environmental Engineering, Yale University, New Haven, CT 06511, USA. E-mail: jordan.peccia@yale.edu

${ }^{4}$ Current address: Department of Civil and Environmental Engineering, Clarkson University, Potsdam, NY 13699, USA.

${ }^{5}$ Current address: Department of Chemical Engineering, Massachusetts Institute of Technology, Cambridge, MA 02139, USA.

Received 21 November 2011; revised 21 February 2012; accepted 22 February 2012; published online 5 April 2012
(Crameri et al., 2006). Exposure to fungal allergens is considered to be a strong risk factor for asthma symptom prevalence and severity, and there is robust evidence to support a relationship between elevated environmental fungal spore counts and asthma attacks (Crameri et al., 2006; Denning et al., 2006). Although less common than allergic disease, invasive fungal infections occur in both immunocompetent and immunocompromised hosts (Pitman et al., 2011). Invasive fungal infections from Candidia, Aspergillus and Cryptococcus spp. are associated with high mortality in immunocompromised individuals (Lin et al., 2001).

Aerodynamic diameter and species diversity are master variables that determine personal exposures and subsequent human health impacts. For a particle of arbitrary shape, size and density, its aerodynamic diameter is uniquely defined as the diameter of a sphere of unit density (that is, $1 \mathrm{~g} \mathrm{~cm}^{-3}$ ) that experiences the same gravitational settling velocity. The size of fungal material controls 
the rate and extent of physical processes that are important for human exposure. These include settling and deposition onto environmental surfaces, deposition in the human respiratory tract, penetration into buildings, resuspension into air, long-range transport and the efficiency of engineered removal systems (Thatcher and Layton, 1995; Yeh et al., 1996; Riley et al., 2002; Nazaroff, 2004; Prospero et al., 2005; Ariya et al., 2009). Large hyphal fragments and multicellular spores that are $>10 \mu \mathrm{m}$ in size, unicellular spores with diameters of $1-10 \mu \mathrm{m}$ and fragments $<1 \mu \mathrm{m}$ combine to permit a broad size distribution of airborne fungal material. The size distribution can also be influenced by the attachment of fungal particles to other particulate matter. Overall, the inherent diversity in fungal particle size, coupled with the strong influence of aerodynamic diameter on the fate, transport and source strength of fungal particles, indicate that size is an important determinant of how taxonomic compositions of airborne fungi are assembled in the atmosphere and in indoor air.

The study reported here investigates the sizeresolved, seasonal diversity of fungi in the atmosphere at one location in the north eastern United States. We use barcoded DNA pyrosequencing technology applied to a fungal genetic marker (Amend et al., 2010) to provide in-depth descriptions of seasonal aerosol fungal diversity collected for eight different size ranges between $0.4 \mu \mathrm{m}$ to $>9 \mu \mathrm{m}$ in aerodynamic diameter. Genus-level and species analyses were performed to document the size-distributed compositions and abundances of allergenic and pathogenic fungi whereas selected allergenic and pathogenic fungal species were enumerated by quantitative PCR (qPCR) to characterize their absolute concentrations and particlesize distributions. Coupling size-resolved aerosol sampling with next generation DNA sequencing approaches allows for an unprecedented description of atmospheric fungal ecology. The results provide important insights into how fungal aerodynamic diameter affects taxonomic composition, and improve our understanding of human inhalation exposure to atmospheric fungal allergens and pathogens.

\section{Materials and methods}

\section{Air sampling}

Air sampling was conducted for four different seasons in 2009-2010 on the rooftop of a five-story building in New Haven, CT, USA $\left(41^{\circ} 18^{\prime} 29^{\prime} \mathrm{N}\right.$ $72^{\circ} 55^{\prime} 43^{\prime} \mathrm{W}$ ). Sampling for the four seasons occurred on the following days: spring 13 May to 10 June 2009; summer 11 August to 8 September 2009; fall 15 October to 12 November 2009; and winter 14 January to 11 February 2010. Two eight-stage non-viable Andersen samplers (aerodynamic diameter $\left(d_{\mathrm{a}}\right)=0.4-0.7, \quad 0.7-1.1, \quad 1.1-2.1, \quad 2.1-3.3$,
3.3-4.7, 4.7-5.8, 5.8-9.0 and $>9.0 \mu \mathrm{m}$; New Star Environmental, Roswell, GA, USA) were deployed to collect airborne particles on glass fiber substrates and operated continuously for the ca. 4-week durations specified above. The cutoff diameters described here are the particle diameters having $50 \%$ collection efficiency. Aerosol samples were collected at an air flow rate of $28.3 \mathrm{lmin}^{-1}$, which were calibrated twice weekly. After collection, the filters were stored at $-20^{\circ} \mathrm{C}$ until subsequent analyses. Outdoor temperature, wind speed and precipitation during the sampling periods are presented in Supplementary Table 1.

\section{DNA extraction}

One-eighth section of the loaded glass fiber filter was used for DNA extraction. Extraction was performed using the PowerMax Soil DNA Isolation Kit (Mobio Laboratory, Carlsbad, CA, USA) with the following modifications. The filter section was enclosed in a 2-ml microcentrifuge tube along with the kit's power beads $(1.0 \mathrm{~g})$, kit's extraction solution $(750 \mu \mathrm{l}), 0.1 \mathrm{~mm}$ diameter glass beads $(300 \mathrm{mg})$ and $0.5 \mathrm{~mm}$ diameter glass beads $(100 \mathrm{mg}$ ). The samples were then homogenized for $5 \mathrm{~min}$ by a bead beater (Model 607; BioSpec Products, Bartlesville, OK, USA). After bead beating, the extracted nucleic acids were purified in accordance with the kit protocol and purified DNA was eluted with $50 \mu \mathrm{l}$ of TE buffer (10 mm Tris-HCl, 1 mм EDTA, $\mathrm{pH}=8.0$ ).

\section{Pyrosequencing of the internal transcribed spacer (ITS) region of $r D N A$}

Sequencing was performed on 20 impactor samples, comprising the four seasons, each with five particlesize stages $\left(d_{\mathrm{a}}>2.1 \mu \mathrm{m}\right)$. Samples with $d_{\mathrm{a}}<2.1 \mu \mathrm{m}$ were not included for the analyses owing to no or weak PCR amplification. Universal fungal primers ITS1F and ITS4 (Larena et al., 1999; Manter and Vivanco, 2007) along with adaptor, key and multiplex identifier sequences were used to amplify the ITS region of fungal rDNA (Supplementary Table 2). The $50 \mu \mathrm{l}$ reaction mixture contained the template DNA ( $2 \mu \mathrm{l}$ sample extract), $1 \times$ PCR Master Mix (Roche Applied Science, Indianapolis, IN, USA) and $0.3 \mu \mathrm{M}$ of each primer. Cycling conditions were: $95^{\circ} \mathrm{C}$ for 5 min of initial denaturation and 35 cycles of $95{ }^{\circ} \mathrm{C}$ for $30 \mathrm{~s}$ of dissociation, $55^{\circ} \mathrm{C}$ for $30 \mathrm{~s}$ of annealing, $72^{\circ} \mathrm{C}$ for $1 \mathrm{~min}$ for each cycle extension and $72^{\circ} \mathrm{C}$ for $10 \mathrm{~min}$ of final extension step. PCR amplicons were purified and concentrations normalized with SequalPrep Normalization Plate (96 well) Kit (Invitrogen, Grand Island, NY, USA). The normalized amplicons were pooled and then further purified by agarose gel extraction (QIAquick Gel Extraction Kit; Qiagen, Valencia, CA, USA). Pyrosequencing of amplicons was performed using the 454 GS FLX Titanium Platform (454 Life Sciences) at the Yale University Center for Genome Analysis. 
DNA sequence processing and analyses

Sequence FASTA and QUAL files were extracted from the machine output file, trimmed and parsed by sequence tag using the Ribosomal Database Project pyrosequencing pipeline (Cole et al., 2005). Trimming removed primers, sequences with one or more undefined base, sequences below a minimum machine quality score of 20 and sequences with a trimmed read length of fewer than $300 \mathrm{bp}$. Trimmed sequences were taxonomically placed using BLASTn ver. 2.2.19 (Altschul et al., 1990) and a maximum E-value of $10^{-5}$ using a database that contained only named fungal ITS sequences (Nilsson et al., 2009). Taxonomic placement was assigned when that species was the sole top hit. In cases of multiple top hits, identity was assigned to the taxonomic level that could be unambiguously identified. Taxonomic placement of fungal genera in their respective phyla, classes and orders was adopted from the Index Fungorum (http://www. indexfungorum.org/names/names.asp). Allergenic and human pathogenic (infectious) fungi were identified through literature searches (Makimura, 2001; Simon-Nobbe et al., 2008) and are listed in Supplementary Tables 3 and 4, respectively. Based on the above classifications and assembled lists in Supplementary Tables 3 and 4 , the relative abundance allergens and pathogens were determined. The method reproducibility based on relative differences of field replicates was generally $<20 \%$ for characterizing relative abundances of fungal species with $>100$ sequences detected per sample. Raw sequencing data have been deposited in the MG-RAST (metagenomics.anl.gov) archive under accession number 4476444.3.

Diversity analyses

UCLUST ver. 1.2.22 (http://www.drive5.com/ uclust) with default settings was used for cluster analysis. Before diversity analyses, the sequence libraries were split within QIIME 1.3.0 (Caporaso et al., 2010) and denoised (Quince et al., 2009; Reeder and Knight, 2009; Quince et al., 2011) to avoid diversity overestimation caused by sequencing errors. Following denoising, the operational taxonomic units (OTUs) were defined based on $97 \%$ similarity (O’Brien et al., 2005; Buée et al., 2009), and the samples were rarified through the QIIME alpha-diversity workflow script. These OTUs were then used as a basis for calculating alpha-diversity metrics, including Chao1 and Shannon indices and rarefaction curves.

\section{Real-time qPCR}

Detailed method descriptions for qPCR of fungal genomes in environmental samples have been published (Yamamoto et al., 2011). The TaqMan method was used to quantify specific allergenic fungi based on well described primer and probe sequences (Haugland and Vesper, 2002). Sequences of primers and probes and the fungal taxa included are listed in Supplementary Tables 2. For the qPCR reaction, $50 \mu \mathrm{l}$ reaction mixtures contained $2 \mu \mathrm{l}$ of template DNA, $1 \times$ TaqMan Universal PCR Master Mix (Applied Biosystems, Carlsbad, CA, USA), $1 \mu \mathrm{M}$ of each primer, and $0.08 \mu \mathrm{M}$ of the probe. Amplification was performed in a real-time PCR system (ABI 7500 Fast Real-time PCR System; Applied Biosystems) at the following cycling conditions for all PCR assays: $50{ }^{\circ} \mathrm{C}$ for $2 \mathrm{~min}, 95^{\circ} \mathrm{C}$ for $15 \mathrm{~min}$ of initial denaturation, and 45 cycles of $95^{\circ} \mathrm{C}$ for $15 \mathrm{~s}$ of dissociation and $60{ }^{\circ} \mathrm{C}$ for $1 \mathrm{~min}$ of annealing and extension. Cycle thresholds were calculated using the auto function in the ABI 7500 software (Applied Biosystems) and all samples were run in triplicate. To test for PCR inhibition, seven randomly selected extracts from air samples collected in this study were added to subsets of diluted Epicoccum nigrum DNA standard and standard curves were produced. No significant inhibition was observed.

To generate qPCR standards for Aspergillus fumigatus (ATCC 34506), Cladosporium cladosporioides (ATCC 16022) and Penicillium chrysogenum (CAES PC1), the spore samples harvested from pure cultures were enumerated by direct microscopy. For Alternaria alternata (PEM 01043) and Epicoccum nigrum (TU BL-3), tissues of the pure-cultured colonies were used to prepare the DNA standards and the original cell counts were back-calculated based on recovered DNA quantities and genome sizes. The accuracy, precision and method detection limits of this methodology are reported elsewhere (Hospodsky et al., 2010; Yamamoto et al., 2011).

Calculations of geometric means and geometric s.d. of aerodynamic diameters

To quantitatively characterize the representative particle-size distributions, geometric means $\left(d_{\mathrm{g}}\right)$ and geometric s.d. $\left(\sigma_{\mathrm{g}}\right)$ of aerodynamic diameters were calculated (Hinds, 1999) in accordance to Equation 1 and by assuming a $20 \mu \mathrm{m}$ cutoff for the top impactor stage.

$$
d_{g}=\exp \left(\frac{\sum n_{i} \ln d_{i}}{N}\right)
$$

where $n_{\mathrm{i}}$ is the measured number of cells or genomes in the ith particle-size interval, $d_{i}$ is the geometric midpoint of the interval, $N$ is the total number of cells or genomes and the summation is carried out over all i. Geometric s.d. was computed in this manner:

$$
\ln \sigma_{g}=\left(\frac{\sum n_{i}\left(\ln d_{i}-\ln d_{g}\right)^{2}}{N}\right)^{1 / 2}
$$

Geometric s.d. were defined to be 'not determined (n.d.)' in case the highest concentration, in terms of $\Delta N / \Delta \log d_{\mathrm{a}}$, was observed for the top impactor stage. 


\section{Results and discussion}

Richness and diversity of airborne fungi

Globally, fungi are broadly diverse (Mueller and Schmit, 2007), with an estimated 1.5 million unique species (Hawksworth, 2001). Here we used 454 pyrosequencing to provide the most comprehensive survey of taxonomic composition of atmospheric fungi reported to date. From the 20 samples collected during four seasons, a total of 15326 ITS sequences were obtained after quality filtering. This value represents $>10$ times increase from the largest previous sequence-based survey of atmospheric fungi (Fröhlich-Nowoisky et al., 2009). The trimmed sequence lengths ranged from 300 to $749 \mathrm{bp}$ with a median length of $491 \mathrm{bp}$. Based on taxonomic classification described in 'Materials and methods', 12864 and 11280 ITS sequences were determined to the genus and species levels, respectively. ITS diversity between fungal genera and species is high (much higher than $18 \mathrm{~S}$ and $28 \mathrm{~S}$ sequence diversity), generally allowing species level taxonomic placement (Nilsson et al., 2008). Overall, 558 different genera and 1172 different species were identified (Supplementary Tables 5 and 6).

Fungal richness and diversity in outdoor air were estimated based on OTU with 97\% sequence similarity (O’Brien et al., 2005; Buée et al., 2009). The number of OTUs ranged from 173 to 545 for each sample (Supplementary Table 7). Rarefaction curves of observed OTUs continued to rise with increasing numbers of sequences (Supplementary Figure 1), suggesting that further increases in sample size will yield even more species. Chao1 estimator predicted 746-5157 OTUs depending on the samples (Supplementary Table 7), which were similar to the fungal richness recently described in forest soil using 454 pyrosequencing (Buée et al., 2009). The diversity metrics reported here are higher than those previously determined for outdoor air based on Chao1 in conjunction with a cloning and Sanger sequencing method (Fröhlich-Nowoisky et al., 2009). In general, richness variation by particle size and by season was small. There was no statistically significant difference of fungal richness by particlesize class $(P>0.05$; Friedman's test using seasons as repeated measures) and season $(P>0.05$; Friedman's test using particle-size classes as repeated measures) although winter samples showed slightly less richness than did other seasons (Supplementary Figure 1 and Supplementary Table 7).

\section{Taxonomic composition of airborne fungi}

Taxonomic compositions of airborne fungi, including allergens and pathogens, were dependent on the aerodynamic diameters. Figure 1a illustrates the proportional distributions of Ascomycota and Basidiomycota phyla in outdoor air. The relative abundance of Ascomycota increases with increasing aerodynamic diameter whereas Basidiomycota were more highly enriched in the smaller particle sizes. This observed tendency was likely because of differences of spore sizes. To examine this hypothesis, we searched for spore sizes of the top three most abundant fungal genera belonging to each phylum. The top three most abundant Ascomycota genera and their averaged relative abundances were Leptosphaerulina $(4.9 \%)$, Epicoccum $(4.2 \%)$ and Cladosporium $(3.5 \%)$, whereas the top three most abundant Basidiomycota genera were Peniophora $(8.6 \%)$, Exidia $(6.8 \%)$ and Stereum $(4.8 \%)$. The reported Ascomycota spore sizes $(\mathrm{L} \times \mathrm{W})$ are: 21-26 $\times 9.5-13 \mu \mathrm{m}$ for Leptosphaerulina (Roux, 1986), 15-25 $\mu \mathrm{m}$ for Epicoccum (Cole and Samson, 1984) and $3-11 \times 2-5 \mu \mathrm{m}$ for Cladosporium (Cole and Samson, 1984). The reported Basidiomycota spore sizes are: $3-3.5 \times 6.5-8 \mu \mathrm{m}$ for Peniophora (Whelden, 1936), 2.5-3.5 × 15-20 $\mu \mathrm{m}$ (basidiospore) and $1 \times 2-4 \mu \mathrm{m}$ (conidia) for Exidia (Ingold, 1995), and $6-7 \times 2.5 \mu \mathrm{m}$ for Stereum (Burt, 1920). Thus, we found spore sizes of the Ascomycota were consistently larger than those of the Basidiomycota, suggesting spore sizes as an important determinant for their aerodynamic diameters.

Consistent with a previous study conducted in Germany (Fröhlich-Nowoisky et al., 2009), Dothideomycetes and Sordariomycetes were the two most abundant fungal classes in airborne Ascomycota (Figure 1b). Dothideomycetes includes genera associated with allergenic fungi such as Alternaria, Epicoccum, Curvularia and Cladosporium. A. alternata is a major allergen associated with the development of asthma in children (Halonen et al., 1997) whereas Cladosporium spp. are abundant and common fungi both indoors and outdoors (Shelton et al., 2002) and are associated with respiratory allergy (D'Amato et al., 1997).

Large proportions of Eurotiomycetes (32\% of total Ascomycota sequences) were found in the winter samples (Figure 1b). This class contains various clinically important fungi including Aspergillus and Penicillium. A. fumigatus is a major fungal allergen (Nierman et al., 2005), and also causes invasive infections such as allergic bronchopulmonary aspergillosis (Greenberger, 2002). The Penicillium genus includes important allergenic species (Schwab et al., 2004).

Agaricomycetes was the most abundant class found in the Basidiomycota sequences (>95\%), in which Russulales and Polyporales were two of the most abundant orders (Figure 1c). Agaricomycetes are mushroom-forming fungi (Hibbett et al., 1997), and generally do not contain described allergenic or pathogenic members, with the exception of some Agaricales (e.g., Schizophyllum commune (Kern and Uecker, 1986)).

Abundance of allergenic and pathogenic fungi Figure 2 illustrates relative abundances of known allergens and infectious pathogens as well as the 22 

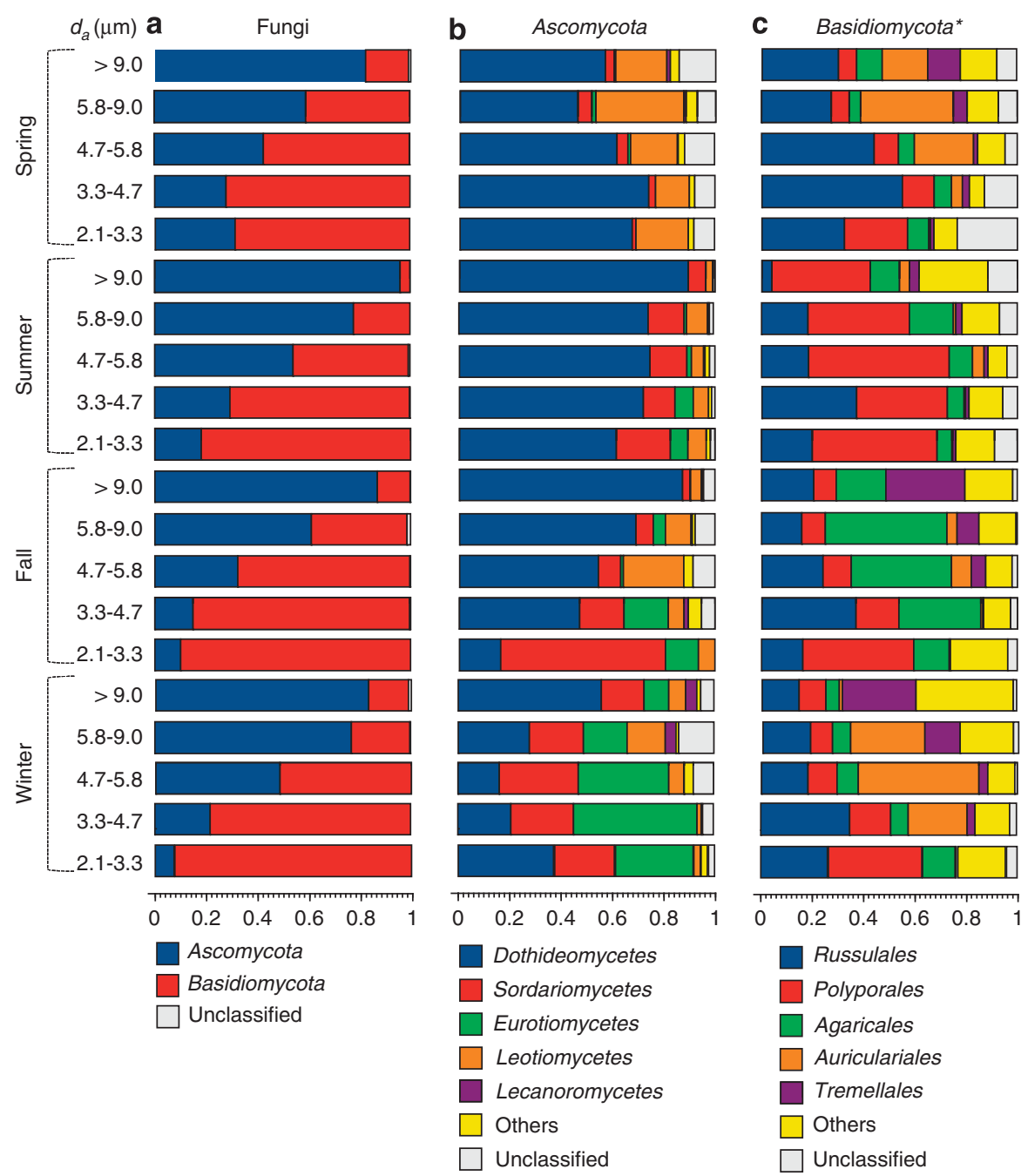

Figure 1 ITS-based proportional distributions of atmospheric fungal phyla (a). Fungal class proportional distribution of the Ascomycota phylum (b). Fungal order proportional distribution of the Basidiomycota phylum (c). "Greater than 95\% of Basidiomycota belonged to the Agaricomycetes class, thus order-level classification was used to provide additional higher-level taxonomic information.

most abundant fungal genera detected by 454 pyrosequencing. The allergens and pathogens in Figure 2 are based on the lists of currently described allergenic or pathogenic fungal species, which are detailed in Supplementary Tables 3 and 4, respectively (Makimura, 2001; Simon-Nobbe et al., 2008). Several species are both allergens and pathogens, and because not all fungal allergens and pathogens have been explored and documented, some species are not included.

The majority of allergenic and pathogenic fungi were members of the Ascomycota phylum (Figure 2). Among them, members of the Alternaria and Epicoccum genera were the most abundant allergenic fungi, and were found mostly in the larger particle-size ranges $\left(d_{\mathrm{a}}>4.7 \mu \mathrm{m}\right)$ (Figure 2). Cladosporium was another abundant allergenic fungal genus, distributed evenly across all the particle-size ranges (Figure 2). Although less abundant, Aspergillus and Penicillium spp. were also detected. Both
Aspergillus and Penicillium occurred mostly in the particle-size range of $d_{\mathrm{a}}<9.0 \mu \mathrm{m}$ (Figure 2).

Medically important members of the Schizophyllum and Cryptococcus genera were two of the most abundant fungal pathogens found in Basidiomycota. Schizophyllum commune has been reported as the causative agent of maxillary sinus infection (Kern and Uecker, 1986) and Cryptococcus neoformans is a well-studied fungal pathogen (Loftus et al., 2005) that causes life-threatening meningitis in immunocompromised patients (Mitchell and Perfect, 1995). Schizophyllum and Cryptococcus were concentrated in different particle-size ranges, $d_{\mathrm{a}}<4.7 \mu \mathrm{m}$ and $d_{\mathrm{a}}>4.7 \mu \mathrm{m}$, respectively, and Schizophyllum was most abundant in the spring (Figure 2).

To date, 150 individual fungal species that contain allergenic proteins in 80 genera have been identified (Simon-Nobbe et al., 2008). In this study, we identified 11 allergenic fungal species in outdoor 


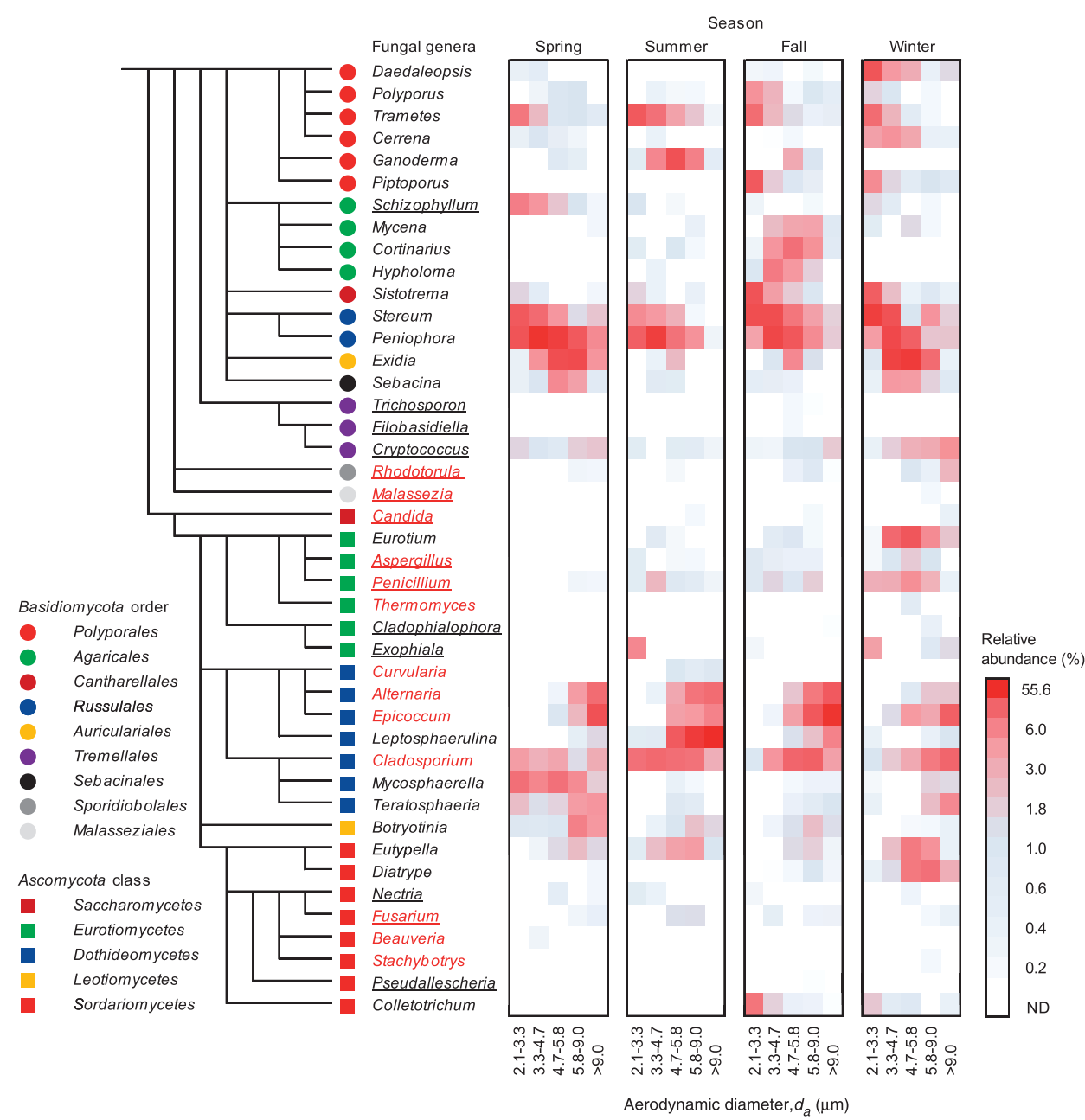

Figure 2 Relative abundances of fungal genera identified in the atmosphere. The most abundant fungal genera, genera containing known allergens (in red) and genera containing infectious pathogenic species (underlined) are listed. A tree was constructed based on taxonomic classifications provided by Index Fungorum. Seven taxonomic levels, that is, phylum, subphylum, class, subclass, order, family and genus, are used to define nodes of the tree. The allergenic and pathogenic genera are defined as genera with allergenic or pathogenic species listed in Supplementary Tables 3 and 4, respectively. Genera shown represent 56\% of the outdoor air sequences.

air (Supplementary Figure 2). The top five most abundant allergenic fungi that were identified to the species level and their averaged relative abundances were Epicoccum nigrum (4.23\%), Cladosporium cladosporioides $(0.27 \%)$, Alternaria alternata $(0.05 \%)$, Thermomyces lanuginosus $(0.05 \%)$ and Penicillium brevicompactum (0.03\%) (Supplementary Figure 3). Five different pathogenic fungal species were also identified (Supplementary Figure S2) out of sixty-six species of described fungal pathogens in Supplementary Table 4, and the two most abundant were Schizophyllum commune $(0.46 \%)$ and Aspergillus fumigatus $(0.02 \%)$ (Supplementary Figure 3). Overall, allergenic fungi comprised $2.8-10.7 \%$ of all taxa in all particle-size ranges. The relative abundance of allergen species increased with increasing aerodynamic diameter (Figure 3). The relative abundance of pathogenic fungi ranged from $0.1 \%$ to $1.6 \%$ of the sequences, and increased with decreasing aerodynamic diameter. Over all particle sizes and seasons, the averaged proportions of allergenic and pathogenic fungal species to total number of ITS sequences were $4.7 \%$ and $0.5 \%$, respectively (Figure 3 ).

\section{Absolute concentrations of particle size-resolved allergenic and pathogenic fungi}

To circumvent sequencing's inability to identify absolute quantities of atmospheric fungi, selected species and groups from the genera Alternaria, Aspergillus, Cladosporium, Epicoccum and Penicillium were chosen for qPCR. These groups were commonly detected by pyrosequencing (Figure 2, Supplementary Figures 2 and 3) and are clinically important allergens and pathogens. Table 1 and Supplementary Table 2 summarize the selectivity of each qPCR assay.

Figure 4 displays seasonal concentrations and particle-size distributions of these selected 
a

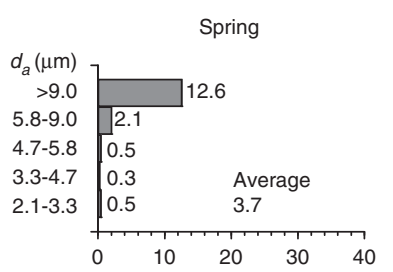

b

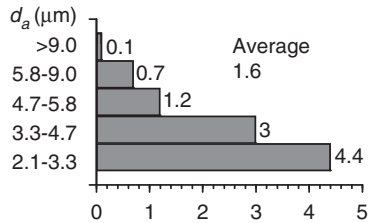

Summer
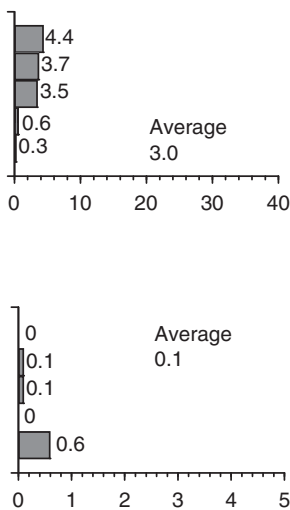

Allergen

Fall

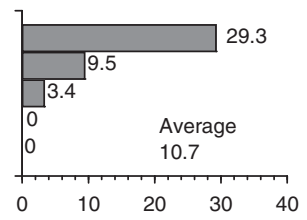

Pathogen

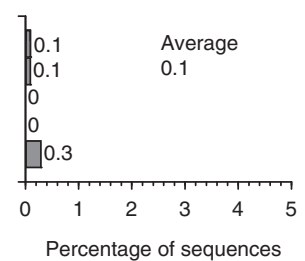

Figure 3 Relative abundances of total allergenic (a) and pathogenic (b) fungal species. The allergenic and pathogenic genera are defined as genera with allergenic or pathogenic species listed in Supplementary Tables 3 and 4, respectively. Average values indicate means of the relative abundances of all particle sizes.

Table 1 Comparison between aerodynamic diameters of airborne fungi and microscopy-based sizes of fungal spores

\begin{tabular}{|c|c|c|c|c|c|c|c|c|c|}
\hline \multirow[t]{2}{*}{$\begin{array}{l}\text { Assay } \\
\text { name }\end{array}$} & \multicolumn{2}{|c|}{$\begin{array}{l}\text { Aerodynamic } \\
\text { diameter } \\
\text { This study }\end{array}$} & \multirow[t]{2}{*}{ Species $^{\mathrm{a}}$} & \multicolumn{4}{|c|}{$\begin{array}{c}\text { Aerodynamic diameter } \\
\text { Previous pure culture studies }\end{array}$} & \multicolumn{2}{|c|}{ Microscopy-based size } \\
\hline & $\begin{array}{c}d_{g} \\
(\mu \mathrm{m})^{\mathrm{b}}\end{array}$ & $\sigma_{g}{ }^{\mathrm{c}}$ & & $d_{g}(\mu m)^{\mathrm{b}}$ & $\sigma_{g}{ }^{c}$ & Method & Reference & $L \times W(\mu m)$ & Reference \\
\hline \multirow[t]{2}{*}{ Afumi } & 4.3 & 1.6 & $\begin{array}{l}\text { Aspergillus } \\
\text { fumigatus }\end{array}$ & $2.14-2.16$ & $1.11-1.13$ & $\begin{array}{l}\text { Aerodynamic } \\
\text { Particle Sizer }\end{array}$ & Reponen et al. (1996) & $2-3.5$ & $\begin{array}{l}\text { Cole and Samson } \\
\text { (1984) }\end{array}$ \\
\hline & & & $\begin{array}{l}\text { Neosartorya } \\
\text { fischeri }\end{array}$ & n.a. & n.a. & n.a. & n.a. & $7-8$ & Tanaka et al. (2011) \\
\hline \multirow[t]{6}{*}{ PenGrp3 } & 4.2 & 1.4 & $\begin{array}{l}\text { Penicillium } \\
\text { chrysogenum }\end{array}$ & $2.6-3.0$ & n.a. & $\begin{array}{l}\text { Aerodynamic } \\
\text { Particle Sizer }\end{array}$ & $\begin{array}{l}\text { Madelin and Johnson } \\
\text { (1992) }\end{array}$ & $2.5-2.5$ & $\begin{array}{l}\text { Madelin and Johnson } \\
\text { (1992) }\end{array}$ \\
\hline & & & P. griseofulvum & n.a. & n.a. & n.a. & n.a. & 2.6 & Fletcher (1969) \\
\hline & & & P. glandicola & n.a. & n.a. & n.a. & n.a. & n.a. & n.a. \\
\hline & & & P. coprophilum & n.a. & n.a. & n.a. & n.a. & n.a. & n.a. \\
\hline & & & P. expansum & n.a. & n.a. & n.a. & n.a. & $3-3.5 \times 2.5-3$ & $\begin{array}{l}\text { Cole and Samson } \\
\text { (1984) }\end{array}$ \\
\hline & & & Eupenicillium spp. & n.a. & n.a. & n.a. & n.a. & $2-5$ & Tanaka et al. (2011) \\
\hline \multirow[t]{2}{*}{ PenAsp1mgb } & 4.2 & 1.4 & $\begin{array}{l}\text { Universal } \\
\text { Aspergillus and } \\
\text { Penicillium sno }\end{array}$ & n.a. & n.a. & n.a. & n.a. & n.a. & n.a. \\
\hline & & & $\begin{array}{l}\text { Paecilomyces } \\
\text { variotii }\end{array}$ & $2.5-2.7$ & n.a. & $\begin{array}{l}\text { Aerodynamic } \\
\text { Particle Sizer }\end{array}$ & $\begin{array}{l}\text { Madelin and Johnson } \\
\text { (1992) }\end{array}$ & $1.3 \times 2.9$ & $\begin{array}{l}\text { Madelin and Johnson } \\
\text { (1992) }\end{array}$ \\
\hline Cclad2 & 5.2 & 1.6 & $\begin{array}{l}\text { Cladosporium } \\
\text { cladosporioides }\end{array}$ & $1.75-1.87$ & $1.14-1.17$ & $\begin{array}{l}\text { Aerodynamic } \\
\text { Particle Sizer }\end{array}$ & Reponen et al. (1996) & $3-11 \times 2-5$ & $\begin{array}{l}\text { Cole and Samson } \\
\text { (1984) }\end{array}$ \\
\hline Aaltr & $>10.4$ & n.d. ${ }^{\mathrm{d}}$ & $\begin{array}{l}\text { Alternaria } \\
\text { alternata }\end{array}$ & 19 & n.a. & $\begin{array}{l}\text { Impaction and } \\
\text { microscopy }\end{array}$ & $\underset{(1993)}{\text { McCartney et al. }}$ & $18-83 \times 7-18$ & $\begin{array}{l}\text { Cole and Samson } \\
\text { (1984) }\end{array}$ \\
\hline Enigr & $>10.5$ & n.d. ${ }^{d}$ & Epicoccum nigrum & n.a. & n.a. & n.a. & n.a. & $15-25$ & $\begin{array}{l}\text { Cole and Samson } \\
\text { (1984) }\end{array}$ \\
\hline
\end{tabular}

Abbreviation: n.a., not available in the literatures.

${ }^{\text {a }}$ Species detectable by qPCR assay.

${ }^{\mathrm{b}}$ Geometric mean aerodynamic diameter.

${ }^{c}$ Geometric s.d. aerodynamic diameter.

${ }^{\mathrm{d}}$ Not determined owing to the skewed particle-size distributions.

allergenic and pathogenic fungi. Geometric means $\left(d_{\mathrm{g}}\right)$ and geometric s.d. $\left(\sigma_{\mathrm{g}}\right)$ of aerodynamic diameters were calculated according to Equations 1 and 2, respectively. Afumi, Cclad2, PenGrp3 and PenAsp1mgb showed aerodynamic diameter peaks of $d_{\mathrm{g}}=3-6 \mu \mathrm{m}$ whereas Aaltr and Enigr were significantly larger, with $d_{\mathrm{g}}>10 \mu \mathrm{m}$ (Figure 4). The observed tendencies were consistent with results characterized by 454 pyrosequencing (Figure 2) where Aspergillus, Cladosporium and Penicillium were enriched in the $<9 \mu \mathrm{m}$, and Alternaria and Epicoccum were enriched in the $>9 \mu \mathrm{m}$ stage. Aspergillus and Penicillium produce unicellular amerospores $<5 \mu \mathrm{m}$, whereas Alternaria and Epicoccum produce multicellular dictyospores $>10 \mu \mathrm{m}$ (Cole and Samson, 1984). The aerodynamic diameters of the unicellular fungi characterized in the atmosphere by qPCR were larger than those determined 


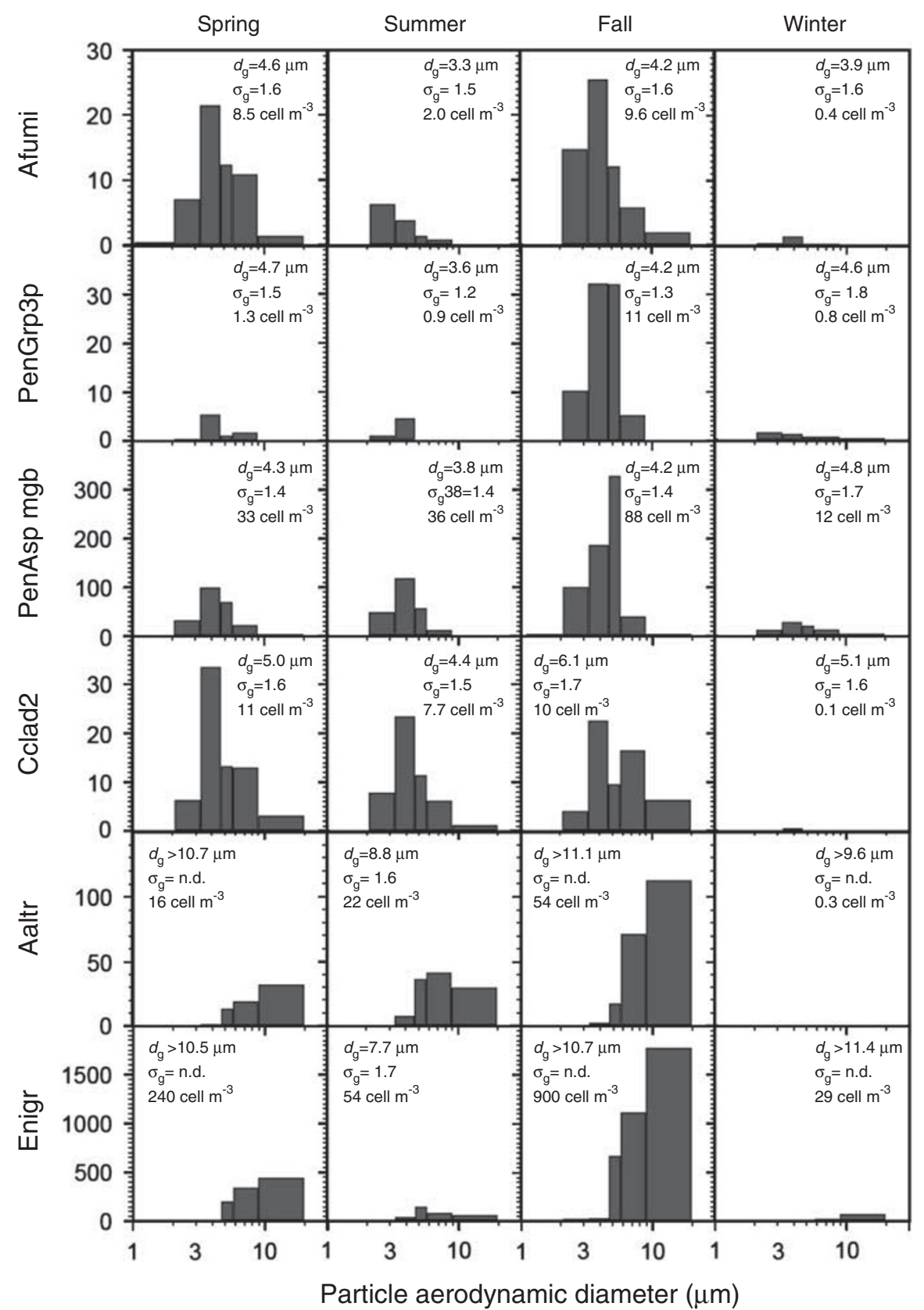

Figure 4 The seasonal particle-size distributions of airborne fungi determined by qPCR ( $y$ axis, $\Delta N / \Delta \log d_{\mathrm{a}}\left(\mathrm{cell} \mathrm{m}^{-3}\right)$ ). An upper limit of particle size for the stage of $>9.0 \mu \mathrm{m}$ is set at $20 \mu \mathrm{m}$ to calculate geometric means of aerodynamic diameter $\left(d_{\mathrm{g}}\right)$ and geometric s.d. $\left(\sigma_{\mathrm{g}}\right)$ of particle-size distributions of airborne fungi. The abbreviation n.d. means 'not determined' owing to the skewed particle-size distributions.

previously by aerosolized pure culture fungi and also larger than microscopically determined fungal dimensions (Table 1). Previous culture-based methods for environmental airborne fungi and time-of-flight based methods applied to pure culture (Madelin and Johnson, 1992; McCartney et al., 1993; Reponen et al., 1996) may underestimate fungal quantities in larger particles as they are incapable of quantifying multiple cells in an aggregate (Heikkila et al., 1988).
Knowledge about the aerodynamic diameter in which fungi are present in the atmosphere is critical for determining the respiratory tract penetration and deposition and thus understanding environmental aspects of allergic airway diseases. Aerodynamic diameter also has great influence on particle behavior in indoor and outdoor air (Riley et al., 2002; Nazaroff, 2004). With the exception of waterdamaged buildings where fungal growth may be 
encouraged, indoor fungal aerosols are generally considered to be of outdoor origins (Burge, 2002). Unicellular allergenic and pathogenic fungi have geometric mean aerodynamic diameters in the $4-5 \mu \mathrm{m}$ range. Particles in this size range have limited efficiency for penetrating building envelopes, are efficiently removed by the ventilation system filters in many buildings, deposit slowly onto upward surfaces, and can be resuspended with moderate efficiency from flooring during human occupancy (Thatcher and Layton, 1995; Riley et al., 2002; Nazaroff, 2004). In contrast, the multicellular spores are typically $>10 \mu \mathrm{m}$. Particles of this size would not penetrate building envelopes, would settle rapidly onto upward surfaces, and would be strongly resuspended during human occupancy. Respiratory deposition patterns are markedly different for 4-5 $\mu \mathrm{m}$ particles as compared with $>10 \mu \mathrm{m}$ particles. The smaller particle sizes, as presented for Aspergillus, Cladosporium and Penicillium show significant penetration to and deposition in the pulmonary regions of the human lung (Yeh et al., 1996; Cho et al., 2005). The larger particles would deposit mainly in the naso-oro-pharyngolaryngeal region of the respiratory tract (Yeh et al., 1996). Indeed, it has been documented that $A$. fumigatus causes allergic bronchopulmonary aspergillosis (Greenberger, 2002) whereas Alternaria and Epicoccum cause allergic fungal sinusitis and are found in nasal sinuses of hypersensitive patients (Noble et al., 1997).

\section{Seasonal variations}

Important seasonal trends with respect to fungal concentration, ecology and size were observed. Consistent with seasonal trends previously observed by culture analysis of airborne fungi in the northeastern United States (Shelton et al., 2002), the concentrations were smallest in winter for all species analyzed whereas the qPCR analyses Aaltr, Afumi, Enigr, PenGrp3 and PenAsp1mgb showed the highest concentrations in fall (Figure 4). The wintertime levels of airborne fungi, while lower than during other seasons, are nevertheless still substantial. Figure 4 shows high relative prevalence of PenAsp mgb and Enigr in winter as compared with the other species reported. These species are also prominent in the outdoor winter sampling data by Shelton et al. (2002). These findings indicate the potential wintertime sources for both background/natural fungal materials as well as contributions from anthropogenic disturbances in the urban setting (e.g., resuspension by motor vehicles). The relative abundance of allergenic species also peaked in the fall, whereas the relative abundance of pathogens was highest in the spring. Although the concentrations of fungi showed clear seasonal trends (Figure 4), with few exceptions (Schizophyllum and Penicillium), the relative abundances of fungal materials did not vary considerably
(Figure 2). Interestingly, the geometric means of aerodynamic diameters were smallest in summer for all the species analyzed (Figure 4).

\section{Conclusions}

Aerodynamic diameter is a crucial parameter for understanding fungal fate and transport in the environment. This study provides the most in-depth characterization of size-resolved taxonomic compositions of atmospheric fungi to date. Results demonstrate that fungal diversity in the atmosphere is higher than previously reported and may rival that of the terrestrial environment. Taxonomic composition of airborne fungi vary strongly with aerodynamic diameter and by season, with allergens clustering in the largest size ranges and the fall season, whereas fungal pathogens were typically observed with aerodynamic diameters $<4.7 \mu \mathrm{m}$ and were most abundant during the spring. In situ measurements of fungal aerodynamic diameter in the atmosphere are different (and typically larger) than diameters determined from pure culture studies. Owing to their ability to identify a broad spectrum of allergenic and pathogenic fungal species, molecular-based methods are an important technology for human exposure studies that seek to better understand the elusive nature of fungal allergy and invasive fungal infections.

\section{Acknowledgements}

Primary funding for this project was provided by the Alfred P Sloan Foundation. NY received a fellowship grant from the Japan Society for the Promotion of Science at the time this research was conducted.

\section{Author contributions}

NY and JP designed the research; NY, JQ, DH and HR-Y performed the research; NY, KB, WWN and JP analyzed the data; NY, KB and JP wrote the paper. The order in which the contributors are listed was agreed amongst the investigators. The first listed (NY) made the greatest contributions to the paper.

\section{References}

Altschul SF, Gish W, Miller W, Myers EW, Lipman DJ. (1990). Basic local alignment search tool. J Mol Biol 215: $403-410$.

Amend AS, Seifert KA, Samson R, Bruns TD. (2010). Indoor fungal composition is geographically patterned and more diverse in temperate zones than in the tropics. P Natl Acad Sci USA 107: 13748-13753.

Ariya PA, Sun J, Eltouny NA, Hudson ED, Hayes CT Kos G. (2009). Physical and chemical characterization of bioaerosols-Implications for nucleation processes. Int Rev Phys Chem 28: 1-32.

Burge HA. (2002). An update on pollen and fungal spore aerobiology. J Allergy Clin Immunol 110: 544-552. 
Burt EA. (1920). The Thelephoraceae of North America. XII. Stereum. Ann Mo Bot Gard 7: 81-249.

Buée $M$, Reich M, Murat C, Morin E, Nilsson RH, Uroz S et al. (2009). 454 Pyrosequencing analyses of forest soils reveal an unexpectedly high fungal diversity. New Phytol 184: 449-456.

Caporaso JG, Kuczynski J, Stombaugh J, Bittinger K, Bushman FD, Costello EK et al. (2010). QIIME allows analysis of high-throughput community sequencing data. Nat Methods 7: 335-336.

Cho SH, Seo SC, Schmechel D, Grinshpun SA, Reponen T. (2005). Aerodynamic characteristics and respiratory deposition of fungal fragments. Atmos Environ 39: 5454-5465.

Cole GT, Samson RA. (1984). The conidia. In: Al-Doory Y, Domson JF (eds) Mould allergy. Lea \& Fibiger: Philadelphia, pp 66-104.

Cole JR, Chai B, Farris RJ, Wang Q, Kulam SA McGarrell DM et al. (2005). The Ribosomal Database Project (RDP-II): sequences and tools for high-throughput rRNA analysis. Nucleic Acids Res 33: D294-D296.

Crameri R, Weichel M, Fluckiger S, Glaser AG, Rhyner C. (2006). Fungal allergies: a yet unsolved problem. Chem Immunol Allergy 91: 121-133.

D’Amato G, Chatzigeorgiou G, Corsico R, Gioulekas D, Jager L, Jager S et al. (1997). Evaluation of the prevalence of skin prick test positivity to Alternaria and Cladosporium in patients with suspected respiratory allergy-a European multicenter study promoted by the subcommittee on aerobiology and environmental aspects of inhalant allergens of the European Academy of Allergology and Clinical Immunology. Allergy 52: 711-716.

Denning DW, O'Driscoll BR, Hogaboam CM, Bowyer P, Niven RM. (2006). The link between fungi and severe asthma: a summary of the evidence. Eur Respir $J$ 27: 615-626.

Elbert W, Taylor PE, Andreae MO, Pöschl U. (2007). Contribution of fungi to primary biogenic aerosols in the atmosphere: wet and dry discharged spores, carbohydrates, and inorganic ions. Atmos Chem Phys 7: 4569-4588.

Fletcher J. (1969). Morphology and nuclear behaviour of germinating conidia of Penicillium griseofulvum. T Brit Mycol Soc 53: 425-432.

Fröhlich-Nowoisky J, Pickersgill DA, Després VR, Poschl U. (2009). High diversity of fungi in air particulate matter. P Natl Acad Sci USA 106: 12814-12819.

Greenberger PA. (2002). Allergic bronchopulmonary aspergillosis. J Allergy Clin Immun 110: 685-692.

Halonen M, Stern DA, Wright AL, Taussig LM, Martinez FD. (1997). Alternaria as a major allergen for asthma in children raised in a desert environment. Am J Respir Crit Care Med 155: 1356-1361.

Haugland R, Vesper S. (2002). Method of Identifying and Quantifying Specific Fungi and Bacteria. U.S. Environmental Protection Agency: USA.

Hawksworth DL. (2001). The magnitude of fungal diversity: the 1.5 million species estimate revisited. Mycol Res 105: 1422-1432.

Heald CL, Spracklen DV. (2009). Atmospheric budget of primary biological aerosol particles from fungal spores. Geophys Res Lett 36: L09806.

Heikkila P, Kotimaa M, Tuomi T, Salmi T, Louhelainen K. (1988). Identification and counting of fungal spores by scanning electron-microscope. Ann Occup Hyg 32: 241-248.
Hibbett DS, Pine EM, Langer E, Langer G, Donoghue MJ. (1997). Evolution of gilled mushrooms and puffballs inferred from ribosomal DNA sequences. P Natl Acad Sci USA 94: 12002-12006.

Hinds WC. (1999). Aerosol technology: Properties, behavior, and measurment of airborne particles. Wiley: New York.

Hospodsky D, Yamamoto N, Peccia J. (2010). Accuracy, precision, and method detection limits of quantitative PCR for airborne bacteria and fungi. Appl Environ Microbiol 76: 7004-7012.

Ingold CT. (1995). Types of reproductive cell in Exidia recisa and Sirobasidium intermediae. Mycol Res 99: 1187-1190.

Kern ME, Uecker FA. (1986). Maxillary sinus infection caused by the Homobasidiomycetous fungus Schizophyllum commune. J Clin Microbiol 23: 1001-1005.

Larena I, Salazar O, Gonzalez V, Julian MC, Rubio V. (1999). Design of a primer for ribosomal DNA internal transcribed spacer with enhanced specificity for ascomycetes. J Biotechnol 75: 187-194.

Lin SJ, Schranz J, Teutsch SM. (2001). Aspergillosis casefatality rate: systematic review of the literature Clin Infect Dis 32: 358-366.

Loftus BJ, Fung E, Roncaglia P, Rowley D, Amedeo P, Bruno D et al. (2005). The genome of the basidiomycetous yeast and human pathogen Cryptococcus neoformans. Science 307: 1321-1324.

Madelin TM, Johnson HE. (1992). Fungal and actinomycete spore aerosols measured at different humidities with an aerodynamic particle sizer. J Appl Bacteriol 72: 400-409.

Makimura K. (2001). Alphabetical List of Pathogenic Fungi Ver.1.2.7. Pathogenic Fungi Database (PFDB) Ver. 1.9.6.1.

Manter DK, Vivanco JM. (2007). Use of the ITS primers, ITS1F and ITS4, to characterize fungal abundance and diversity in mixed-template samples by qPCR and length heterogeneity analysis. J Microbiol Meth 71: 7-14.

McCartney HA, Schmechel D, Lacey ME. (1993). Aerodynamic diameter of conidia of Alternaria species. Plant Pathol 42: 280-286.

Mitchell TG, Perfect JR. (1995). Cryptococcosis in the era of AIDS-100 years after the discovery of Cryptococcus neoformans. Clin Microbiol Rev 8: 515-548.

Mueller GM, Schmit JP. (2007). Fungal biodiversity: what do we know? what can we predict? Biodivers Conserv 16: $1-5$.

Nazaroff WW. (2004). Indoor particle dynamics. Indoor Air 14: 175-183.

Nierman WC, Pain A, Anderson MJ, Wortman JR, Kim HS, Arroyo J et al. (2005). Genomic sequence of the pathogenic and allergenic filamentous fungus Aspergillus fumigatus. Nature 438: 1151-1156.

Nilsson RH, Bok G, Ryberg M, Kristiansson E, Hallenberg N. (2009). A software pipeline for processing and identification of fungal ITS sequences. Source Code Biol Med 4: 1.

Nilsson RH, Kristiansson E, Ryberg M, Hallenberg N, Larsson KH. (2008). Intraspecific ITS variability in the kingdom fungi as expressed in the international sequence databases and its implications for molecular species identification. Evol Bioinform 4: 193-201.

Noble JA, Crow SA, Ahearn DG, Kuhn FA. (1997). Allergic fungal sinusitis in the southeastern USA: involvement 
of a new agent Epicoccum nigrum Ehrenb ex Schlecht 1824. J Med Vet Mycol 35: 405-409.

O’Brien HE, Parrent JL, Jackson JA, Moncalvo JM Vilgalys R. (2005). Fungal community analysis by large-scale sequencing of environmental samples. Appl Environ Microbiol 71: 5544-5550.

Pitman SK, Drew RH, Perfect JR. (2011). Addressing current medical needs in invasive fungal infection prevention and treatment with new antifungal agents, strategies and formulations. Expert Opin Emerg Drugs 16: $559-586$

Prospero JM, Blades E, Mathison G, Naidu R. (2005). Interhemispheric transport of viable fungi and bacteria from Africa to the Caribbean with soil dust. Aerobiologia 21: 1-19.

Quince C, Lanzen A, Curtis TP, Davenport RJ, Hall N, Head IM et al. (2009). Accurate determination of microbial diversity from 454 pyrosequencing data. Nat Methods 6: 639-641.

Quince C, Lanzen A, Davenport RJ, Turnbaugh PJ. (2011). Removing noise from pyrosequenced amplicons BMC Bioinform 12: 38 .

Reeder J, Knight R. (2009). The 'rare biosphere': a reality check. Nat Methods 6: 636-637.

Reponen T, Willeke K, Ulevicius V, Reponen A Grinshpun SA. (1996). Effect of relative humidity on the aerodynamic diameter and respiratory deposition of fungal spores. Atmos Environ 30: 3967-3974.

Riley WJ, McKone TE, Lai ACK, Nazaroff WW. (2002). Indoor particulate matter of outdoor origin: importance of size-dependent removal mechanisms. Environ Sci Technol 36: 200-207.
Roux C. (1986). Leptosphaerulina chartarum sp.nov., the teleomorph of Pithomyces chartarum. Trans Br Mycol Soc 86: 319-323.

Schwab CJ, Cooley JD, Jumper CJ, Graham SC, Straus DC. (2004). Allergic inflammation induced by a Penicillium chrysogenum conidia-associated allergen extract in a murine model. Allergy 59: 758-765.

Shelton BG, Kirkland KH, Flanders WD, Morris GK. (2002). Profiles of airborne fungi in buildings and outdoor environments in the United States Appl Environ Microbiol 68: 1743-1753.

Simon-Nobbe B, Denk U, Poll V, Rid R, Breitenbach M. (2008). The spectrum of fungal allergy. Int Arch Allergy Immunol 145: 58-86.

Tanaka K, Yamaguchi N, Baba T, Amano N, Nasu M. (2011). Rapid enumeration of low numbers of moulds in tea based drinks using an automated system. Int J Food Microbiol 145: 365-369.

Thatcher TL, Layton DW. (1995). Deposition, resuspension, and penetration of particles within a residence. Atmos Environ 29: 1487-1497.

Whelden RM. (1936). A comparative study of basidia and cystidia in Peniophora livida. Am $J$ Bot 23: 539-545.

Yamamoto N, Shendell DG, Peccia J. (2011). Assessing allergenic fungi in house dust by floor wipe sampling and quantitative PCR. Indoor Air 21: 521-530.

Yeh HC, Cuddihy RG, Phalen RF, Chang IY. (1996). Comparisons of calculated respiratory tract deposition of particles based on the proposed NCRP model and the new ICRP66 model. Aerosol Sci Tech 25: $134-140$.

Supplementary Information accompanies the paper on The ISME Journal website (http://www.nature.com/ismej) 